\title{
Determination and Evaluation of Bioavailability of Vitamins from Different Multivitamin Supplements Using a Pig Model
}

\author{
Pan Yang ${ }^{1}$, Huakai Wang ${ }^{1}$, Longxian $\mathrm{Li}^{1}{ }^{1}$, Nan Zhang ${ }^{1}$ and Yongxi Ma ${ }^{1,2, *(\mathbb{D})}$ \\ 1 State Key Laboratory of Animal Nutrition, College of Animal Science and Technology, China Agricultural \\ University, Beijing 100193, China; ypan23@cau.edu.cn (P.Y.); huakaiwhk@cau.edu.cn (H.W.); \\ S20193040586@cau.edu.cn (L.L.); s20203040629@cau.edu.cn (N.Z.) \\ 2 Ministry of Agriculture and Rural Affairs Feed Industry Centre, Beijing 100193, China \\ * Correspondence: mayongxi@cau.edu.cn; Tel.: +86-10-6273-4266
}

Citation: Yang, P.; Wang, H.; Li, L.; Zhang, N.; Ma, Y. Determination and Evaluation of Bioavailability of Vitamins from Different Multivitamin Supplements Using a Pig Model. Agriculture 2021, 11, 418. https:// doi.org/10.3390/agriculture11050418

Academic Editor: Dejan Škorjanc and Manja Zupan Šemrov

Received: 24 March 2021

Accepted: 1 May 2021

Published: 6 May 2021

Publisher's Note: MDPI stays neutral with regard to jurisdictional claims in published maps and institutional affiliations.

Copyright: () 2021 by the authors. Licensee MDPI, Basel, Switzerland. This article is an open access article distributed under the terms and conditions of the Creative Commons Attribution (CC BY) license (https:// creativecommons.org/licenses/by/ $4.0 /)$.

\begin{abstract}
This study was performed to evaluate the plasma vitamin kinetic behavior following oral vitamin supplement administration in pigs, and to determine the bioavailability of vitamins. A total of 36 pigs (fitted with jugular catheters) with an average body weight of $25 \pm 2.24 \mathrm{~kg}$ were divided into three treatment groups: (1) placebo, (2) non-microencapsulated multivitamins supplement, or (3) lipid matrix microencapsulated multivitamins supplement. The blood samples were obtained starting premeal until $72 \mathrm{~h}$ post-meal for plasma vitamin analysis. Pharmacokinetic parameters were modeled with a non-compartmental method. The AUC (Area under the curve) from the time of dosing to the time of the last observation, $\mathrm{C}_{\max }$ (Maximum observed concentration), and MRT (Mean residence time) of $\alpha$-tocopherol from oral non-microencapsulated supplement were significantly lower than oral microencapsulated supplement $(p<0.01)$. The average relative bioavailability of vitamin A (VA) and vitamin E (VE) from microencapsulated supplement was greater than that from nonmicroencapsulated supplement, but relative bioavailability of vitamin $\mathrm{K}_{3}\left(\mathrm{VK}_{3}\right)$ and water-soluble vitamins from microencapsulated supplement was lower than non-microencapsulated supplement. The AUC and $C_{\max }$ of menadione, thiamine, and riboflavin from microencapsulated supplement were significantly lower than these parameters from oral non-microencapsulated supplement. Lipid matrix microencapsulation was able to delay absorption and improved the bioavailability of VE, whereas there were limited effects of microencapsulation on vitamin $\mathrm{D}(\mathrm{VD}), \mathrm{VK}_{3}$, and water-soluble vitamins.
\end{abstract}

Keywords: bioavailability; kinetics behavior; pig; pharmacokinetic analysis; vitamins

\section{Introduction}

With the development of the vitamin industry, multivitamin supplements are widely used. Vitamins are highly biologically active organic substances; they are a special type of nutrients necessary for the normal life and growth of animals [1]. Vitamins are always needed, they are physiologically regulated and controlled. The metabolism of vitamins is of great importance for growth, health, development, reproduction, and immunity [2]. Vitamin A is usually crucial for normal vision, protection of the epithelium, resistance against infection, improving ovulation, and implantation of the embryo [3]. The biofunction of vitamin $\mathrm{D}$ is the efficient absorption and homeostasis of calcium and phosphorus and therefore is required for normal mineralization of bones [4]. Vitamin E has antioxidant function as a peroxyl radical scavenger, and vitamin $K$, referred to as the coagulation vita$\mathrm{min}$, is indispensable for maintaining the function of the blood coagulation system [1,5]. The water-soluble vitamins of the B group act as co-enzymes. Each coenzyme is involved in the metabolism of amino acids, carbohydrates, and fat $[1,6]$.

Powered by advanced chemical synthesis and delivery systems, encapsulation technology has also been used in animal feed, which provides a physical or chemical barrier to isolate the core substance from the surroundings until released in the target site $[7,8]$. Microencapsulation can control the concentration of nutrients in the peripheral circulation 
through slow release in the intestine, improve the body's utilization of nutrients, and prevent nutrient degradation in the processing, storage process, and digestive tract $[9,10]$. Lipid matrix microencapsulation has been widely applied to deliver biological active substances to the host's gut $[11,12]$. However, there is a limitation of information on the plasma release of vitamins when feeding the lipid matrix microencapsulated supplement to pigs. This study hypothesized that the vitamin supplement with lipid matrix (commerciallyavailable) could slowly release vitamins in pigs' intestines. Therefore, the objectives of this study were to investigate the pharmacokinetics of vitamins in plasma after a single oral administration of different forms of multivitamin supplements to pigs and provide a theoretical basis and data to support the application of vitamins.

\section{Materials and Methods}

\subsection{Experimental Materials}

Deionized water was used to prepare all aqueous solutions. A standard was purchased from Sigma-Aldrich (St. Louis, MO, USA). The methanol was high-performance liquid chromatography (HPLC) grade and was purchased from Fisher Scientific (Waltham, MA, USA). Other chemicals were analytical grade and obtained from Sinopharm Chemical Reagent LTD (Shanghai, China). The blend of vitamins was embedded in lipid matrix microparticles (Wellroad Animal Health Co. Ltd., Taiyuan, China). The components of the lipid matrix vitamin supplement were hydrogenated fat for the matrix material and vitamins as core ingredients embedded (microencapsulated) within the lipid matrix. The vitamin sources were retinyl esters, cholecalciferol, $\alpha$-tocopherol acetate, menadione sodium bisulfite, thiamine mononitrate, riboflavin, nicotinic acid, calcium pantothenate, pyridoxine hydrochloride, biotin, folacin, and cyanocobalamin.

\subsection{Animal, Surgery and Treatment}

A total 36 healthy castrated male pigs (Duroc $\times$ Landrace $\times$ Yorkshire) were selected in this study; they were weaned at 28 days of age and subsequently adapted to a basal diet without containing additional vitamin supplements. Diet was formulated to meet net energy, amino acids, and mineral requirements for pigs according to the National Research Council [6], which was in line with commercial practice (Table 1).

One week before the experiment ( $63 \mathrm{~d}$ of age), pigs were housed individually in metabolism cages and adapted to twice-daily meal feeding at a rate of $500 \mathrm{~g} / \mathrm{meal}$. Midway through this period, pigs were anesthetized by an intramuscular injection of $7 \mathrm{mg} / \mathrm{kg}$ body weight of Zoletil (Virbac Laboratories, Carros, France), and $200 \mu \mathrm{g} / \mathrm{kg}$ body weight of Butorphanol (Intervet International, Boxmeer, The Netherlands) was subsequently injected as a painkiller, then catheters were inserted in the jugular veins. Once the catheter was in place, the catheter was taped to the animal. After operation, an antibiotic was intramuscularly injected to prevent infections. Catheters were flushed daily with heparinized sterile saline to prevent blockage. This procedure was described previously $[13,14]$. At the day before the start of the experiment, pigs fasted overnight except for water so that the experimental meal containing the tested substance could be finished in a short time.

The average body weight of animals was $25 \pm 2.24 \mathrm{~kg}$ on the day before the start of the experiment. They were randomly allocated to one of three treatments: (1) placebo, (2) nonmicroencapsulated (normal form) multivitamin supplement, and (3) microencapsulated (lipid matrix) multivitamin supplement. These vitamin supplements were formulated to contain identical levels of vitamins. The vitamin supplement provided per kilogram of diet contained: 13,500 IU of retinyl acetate, 3000 IU of cholecalciferol, 30.0 IU of $\alpha$-tocopherol acetate (fat-soluble form), $3.0 \mathrm{mg}$ of menadione sodium bisulfite, $3.0 \mathrm{mg}$ of thiamine mononitrate, $6.0 \mathrm{mg}$ of riboflavin, $30.0 \mathrm{mg}$ of nicotinic acid, $18.0 \mathrm{mg}$ of calcium pantothenate, $3.0 \mathrm{mg}$ of pyridoxine hydrochloride, $0.03 \mathrm{mg}$ of biotin, $0.12 \mathrm{mg}$ of folacin, and $24.0 \mu \mathrm{g}$ of cyanocobalamin. The dosage of vitamins was chosen based on a survey in pig industry, which showed that the commercial vitamin usage for pigs in China [15]. On d 0, before providing the tested substances, a blood sample (time $0 \mathrm{~h}$ ) was collected. Subsequently, pigs 
fed the basal diet containing placebo, non-microencapsulated (normal form) multivitamins supplement, or microencapsulated (lipid matrix) multivitamins supplement, respectively. No consumed feed was left in this study for each pig.

Table 1. Ingredient composition of the experimental diet (\%, as-fed basis).

\begin{tabular}{cc}
\hline Item & Percent \\
\hline Corn & 69.00 \\
Soybean meal & 23.62 \\
Soybean oil & 3.18 \\
Dicalcium phosphate & 1.20 \\
Limestone & 0.91 \\
Salt & 0.30 \\
L-lysine HCL & 0.68 \\
DL-methionine & 0.13 \\
L-threonine & 0.24 \\
Tryptophan & 0.04 \\
L-valine & 0.20 \\
Trace-mineral premix 1 & 0.50 \\
Total & 100.00 \\
Calculated nutritional values & \\
Net energy (Kcal/kg) & 2412.00 \\
Crude protein & 17.31 \\
SID Lysine & 1.23 \\
SID Methionine & 0.36 \\
SID Threonine & 0.73 \\
SID Tryptophan & 0.20 \\
SID Valine & 0.78 \\
Total Calcium & 0.69 \\
STTD Phosphorus & 0.34 \\
\hline ingling
\end{tabular}

SID, standardized ileal digestible; STTD, standardized total tract digestible; ${ }^{1}$ Trace mineral premix provided the following per $\mathrm{kg}$ of diet: Manganese $(\mathrm{MnO}), 30 \mathrm{mg}$; Iron $\left(\mathrm{FeSO}_{4} \cdot \mathrm{H}_{2} \mathrm{O}\right), 100 \mathrm{mg}$; Zinc $(\mathrm{ZnO}), 80 \mathrm{mg}$; Copper $\left(\mathrm{CuSO}_{4} \cdot 5 \mathrm{H}_{2} \mathrm{O}\right), 90 \mathrm{mg}$; Iodine (KI), $0.25 \mathrm{mg}$; Selenium $\left(\mathrm{Na}_{2} \mathrm{SeO}_{3}\right), 0.15 \mathrm{mg}$.

The time of providing the tested substances was set as time 0 . Subsequently, jugular blood specimens were taken at 1,3, 6, 9, 12, 16, 24, 48, and $72 \mathrm{~h}$ post-treatment. These time points were designed according to previous study [14]. Blood sampling was carefully conducted to avoid any excitement of pigs. These blood samples were collected in tubes containing ethylenediaminetetraacetic acid, and plasma was isolated after centrifugation $(3000 \times g)$ at $4{ }^{\circ} \mathrm{C}$ for $10 \mathrm{~min}$. plasma was transferred to cryovials for storage at $-80^{\circ} \mathrm{C}$ until analyzed.

\subsection{Laboratory Analysis}

For the extraction of retinol, plasma proteins were precipitated with ethanol and vortexed for mixing. Subsequently, the sample was mixed with n-hexane $(500 \mu \mathrm{L})$ for extraction. The organic layers were moved to dry under a stream of nitrogen. The dried sample was reconstituted with methanol $(100 \mu \mathrm{L})$ by vortexing. The quantitative determination was performed by injection of $35 \mu \mathrm{L}$ into a high-performance liquid chromatography (HPLC) machine (Agilent Technologies Inc., Santa Clara, CA, USA). Absorbance was monitored at $350 \mathrm{~nm}$ to maximize the detection of retinol, and a mobile phase of $98 \%$ methanol was run at a flow rate of $1 \mathrm{~mL} / \mathrm{min}$. The limitation of detection for retinol was $0.01 \mu \mathrm{g} / \mathrm{mL}$. The 25-hydroxyvitamin $\mathrm{D}_{3}$ concentrations in the blood were detected and measured using a combination HPLC and mass spectrometry techniques, the flow rate was $0.5 \mathrm{~mL} / \mathrm{min}$ with a gradient of mobile phase made of deionized water containing $0.1 \%$ formic acid and methanol containing $0.1 \%$ formic acid, the limitation of detection for 25 -hydroxyvitamin $\mathrm{D}_{3}$ was $2.5 \mathrm{ng} / \mathrm{mL}$. The quantification of $\alpha$-tocopherol in plasma was performed by the HPLC method described previously [16]. Briefly, $1 \mathrm{~mL}$ of plasma was extracted by $1 \mathrm{~mL}$ of ethanol which contained $0.15 \%$ BHT for inhibiting autoxidation of tocopherol, and $3 \mathrm{~mL}$ of n-hexane containing $0.025 \%$ butylated hydroxytoluene. After mixing and centrifuging, the supernatant 
$(2 \mathrm{~mL})$ was removed into a clean tube and brought to dryness using a stream of nitrogen, and the dried sample was reconstituted with $200 \mu \mathrm{L}$ of methanol. This quantitative determination was performed by HPLC system, which equipped an octadecylsilane column $(250 \times 4.6 \mu \mathrm{m}$, Agilent Technologies Inc., Santa Clara, CA, USA). Absorbance was monitored at $230 \mathrm{~nm}$ to maximize the detection of $\alpha$-tocopherol, and a mobile phase of $100 \%$ methanol was run at a flow rate of $1 \mathrm{~mL} / \mathrm{min}$. The limitation of detection for $\alpha$-tocopherol was $0.1 \mu \mathrm{g} / \mathrm{mL}$. To determine the concentration of menadione in plasma, the sample was mixed with two volumes of methanol for precipitating proteins. After centrifugation, the supernatant was removed into a new plastic tube, and extracted by n-hexane. The supernatant (upper organic phase) was removed again into a clean tube and concentrated with a stream of nitrogen. After drying, the sample was reconstituted with $100 \mu \mathrm{L}$ of methanol, and $50 \mu \mathrm{L}$ of subsample was injected for detection through LC MS/MS (Thermo Fisher Scientific, Waltham, MA, USA). The liquid chromatography was run at a flow rate of $0.3 \mathrm{~mL} / \mathrm{min}$ with a gradient of mobile phase made of deionized water containing $0.1 \%$ formic acid and methanol. The limitation of detection for menadione was $0.1 \mathrm{ng} / \mathrm{mL}$. Liquid chromatography-mass spectrometry technique was also used to determine the level of thiamine, riboflavin, pyridoxal, biotin, pantothenic acid, and cyanocobalamin in blood. The liquid chromatography was run at a flow rate of $0.5 \mathrm{~mL} / \mathrm{min}$ with a gradient of the mobile phase made of $0.1 \%$ formic acid containing $5 \mathrm{mM}$ ammonium formate water and $0.1 \%$ formic acid in methanol; vitamins were quantified using triple quadruple mass spectrometer. The limitations of detection were $0.1 \mathrm{ng} / \mathrm{mL}$ for thiamine, $5.0 \mathrm{ng} / \mathrm{mL}$ for riboflavin, $0.25 \mathrm{ng} / \mathrm{mL}$ for pyridoxal, $0.25 \mathrm{ng} / \mathrm{mL}$ for biotin, $2.5 \mathrm{ng} / \mathrm{mL}$ for pantothenic acid, and $2.5 \mathrm{ng} / \mathrm{mL}$ for cyanocobalamin.

\subsection{Pharmacokinetics and Data Analysis}

The pharmacokinetic data for folic acid and niacin were unavailable because kinetic changes in plasma concentrations of folic acid and niacin were not observed in the present study. Pharmacokinetic curves for the two different oral supplements were edited by Microsoft Office 2019 Excel (Microsoft Corporation, Redmond, WA, USA) and presented by professional software package (GraphPad Software, San Diego, CA, USA). The timeplasma concentration profiles of vitamins were analyzed using noncompartmental analysis. The elimination half-life $\left(t_{1 / 2 \beta}\right)$ was calculated by the equation: $t_{1 / 2 \beta}=\ln (2) \lambda_{z}$, where $\lambda_{z}$ was estimated from the terminal slope of the plasma concentration versus time curve. Mean residence time (MRT) represents the average amount of time a nutrient molecule remains in the compartment, which was equaled to area under the moment curve (AUMC) divided by area under a concentration of vitamin versus time curve (AUC). The AUMC and AUC were calculated using an integrated tool in WinNonlin (Pharsight, CA, USA). The peak time $\left(\mathrm{T}_{\max }, \mathrm{h}\right)$ is the time at which the body displays the maximum plasma concentration $\left(C_{\max }\right)$, and the maximum concentration was determined by the concentration at $\mathrm{T}_{\max }$. The relative bioavailability $(\mathrm{F})$ between microencapsulated and non-microencapsulated vitamin supplements of administration was determined by the ratio of the AUC of vitamin from lipid matrix microencapsulated supplement to the AUC of vitamin from non-microencapsulated supplement.

The data were checked for normality and homogeneity of variance by histograms and formal statistical tests as part of the UNIVARIATE procedure of SAS (SAS Inst. Inc., Cary, NC, USA). All pharmacokinetic analysis for each pig was conducted using the noncompartmental model by a pharmacokinetic software package (WinNonlin, Pharsight, CA, USA). Pharmacokinetic parameters from treatment groups were analyzed as a $t$-test (SAS Inst. Inc., Cary, NC, USA). Significant differences were declared at $p<0.05$. Differences of $0.05 \leq p<0.10$ were considered a trend toward significance.

\section{Results}

\subsection{The Pharmacokinetics of Fat-Soluble Vitamins}

All fat-soluble vitamins showed typical appearance and disappearance with peak values at around 7, 12, 8-12, and 8-9 h after administration for vitamin A, D, E, and K 
(Figures 1-4) regardless of encapsulation with no difference in $T_{\max }$. Based on pharmacokinetics (Table 2), Vitamin $\mathrm{D}_{3}$ had no effect between microencapsulation. Retinol tended to be higher AUC in microencapsulated vitamin supplement (MVS) than non-microencapsulated vitamin supplement (NMVS). Alpha-tocopherol has higher $\mathrm{C}_{\max }, \mathrm{AUC}$, and MRT in MVS than NMVS. In contrast, vitamin K has higher $\mathrm{C}_{\max }$ and AUC in NMVS than MVS. Relative bioavailability of MVS to NMVS was $170.40 \%, 98.11 \%, 182.39 \%$, and $57.13 \%$ for vitamin A, $\mathrm{D}, \mathrm{E}$, and $\mathrm{K}$, respectively.

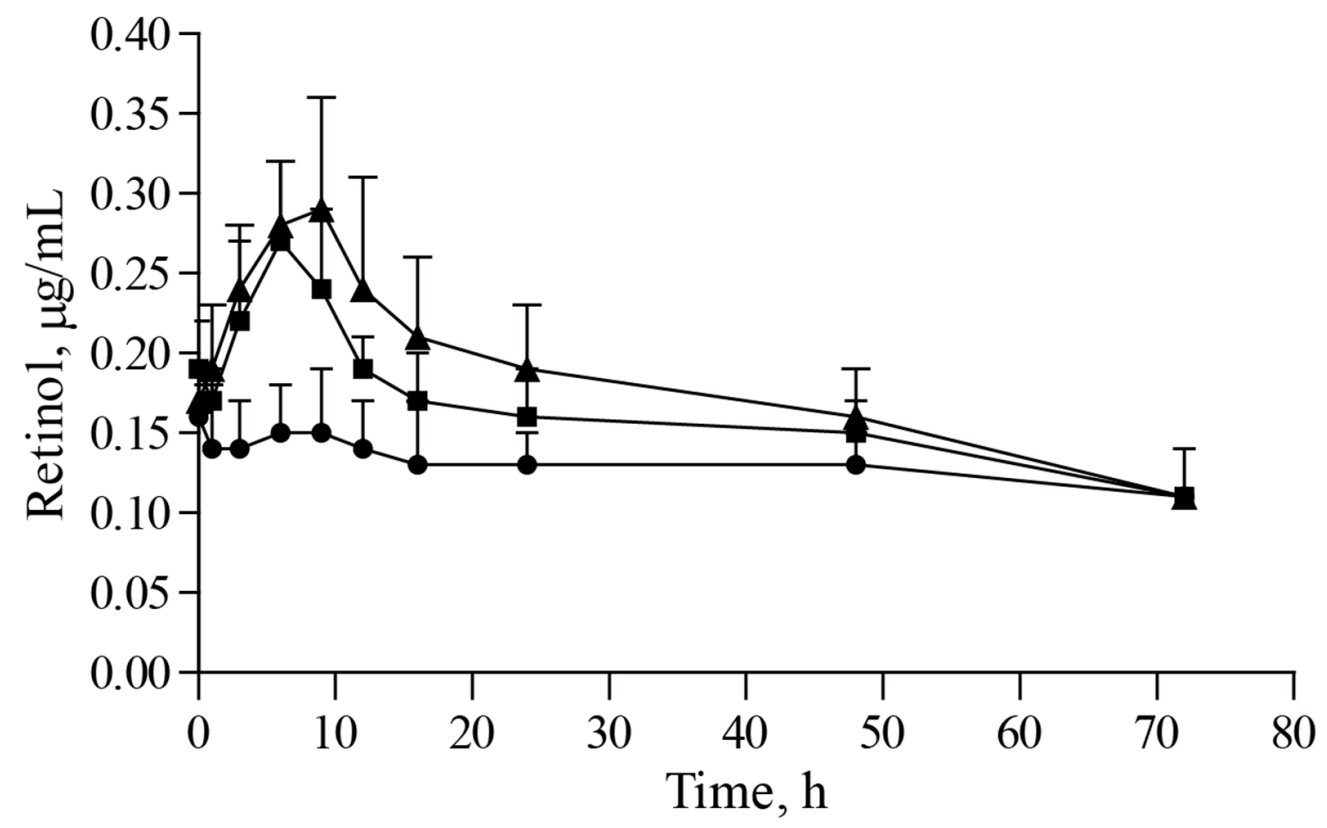

Figure 1. The plasma concentration of retinol versus time. The concentration of retinol in plasma from 0 to $72 \mathrm{~h}$ after oral placebo $(\bullet)$, non-microencapsulated vitamin supplement $(\mathbf{\square})$, and microencapsulated vitamin supplement $(\mathbf{\Lambda})$, respectively. Error bars represent standard deviations.

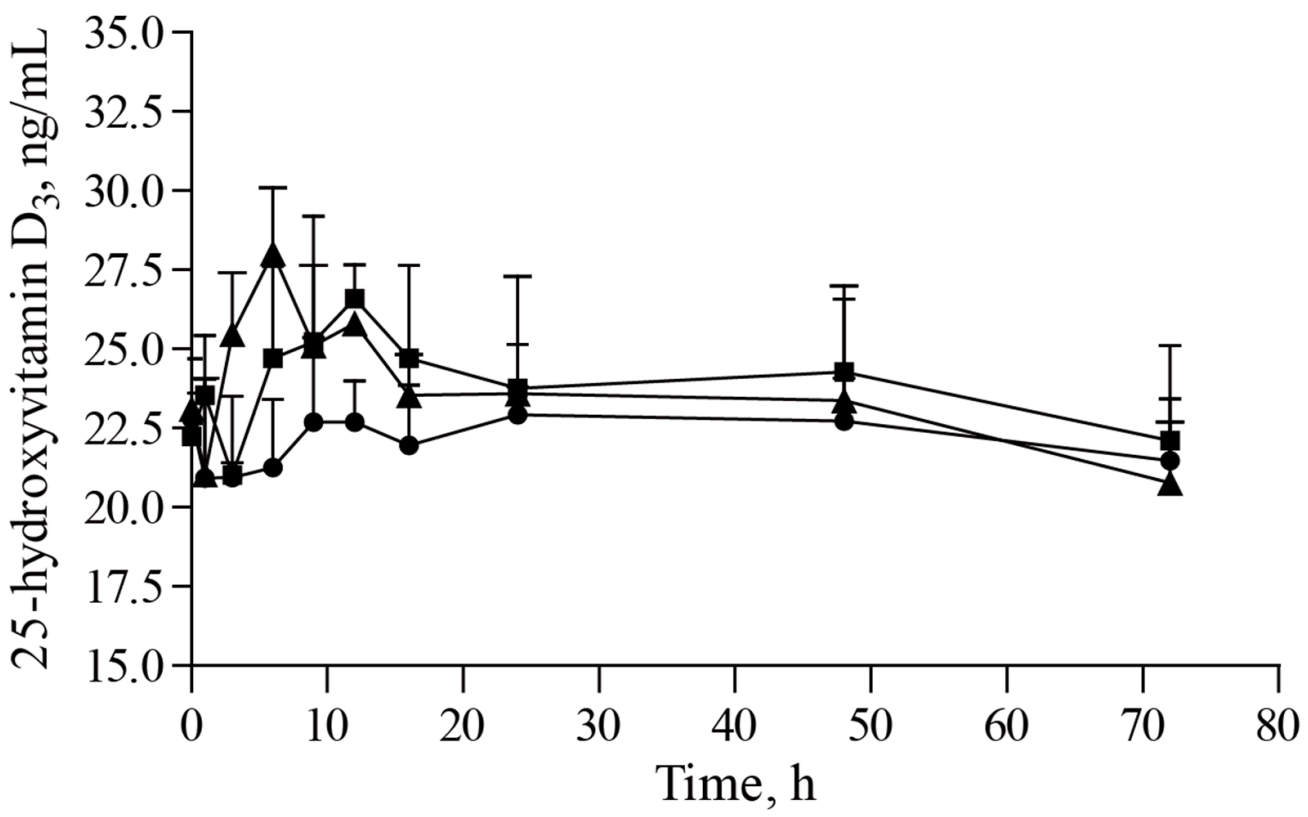

Figure 2. The plasma concentration of 25-hydroxyvitamin $\mathrm{D}_{3}$ versus time. The concentration of 25-hydroxyvitamin $\mathrm{D}_{3}$ in plasma from 0 to $72 \mathrm{~h}$ after oral placebo $(\bullet)$, non-microencapsulated vitamin supplement $(\boldsymbol{\square})$, and microencapsulated vitamin supplement $(\mathbf{\Lambda})$, respectively. Error bars represent standard deviations. 


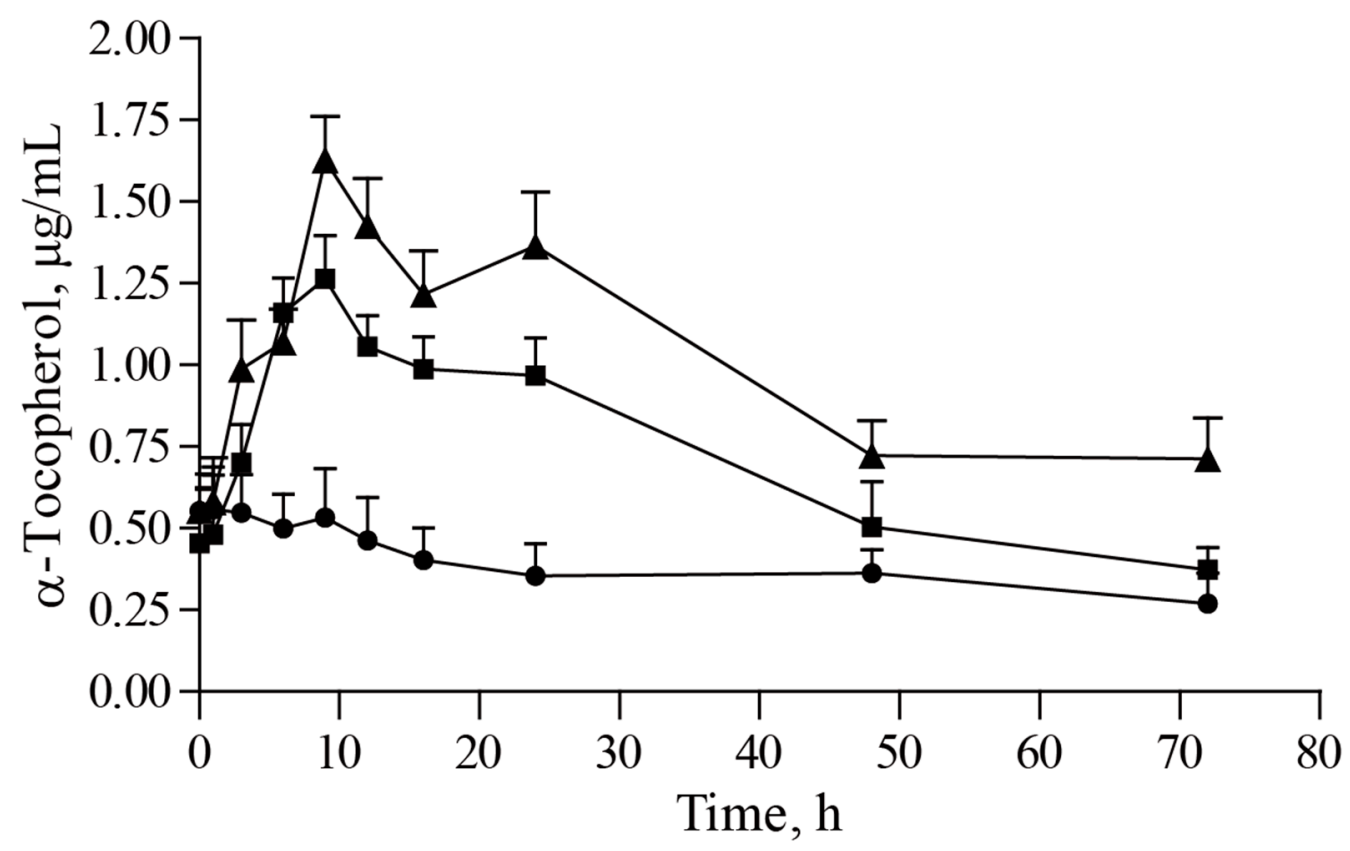

Figure 3. The plasma concentration of $\alpha$-tocopherol versus time. The concentration of $\alpha$-tocopherol in plasma from 0 to $72 \mathrm{~h}$ after oral placebo $(\bullet)$, non-microencapsulated vitamin supplement $(\mathbf{\square})$, and microencapsulated vitamin supplement $(\boldsymbol{\Lambda})$, respectively. Error bars represent standard deviations.

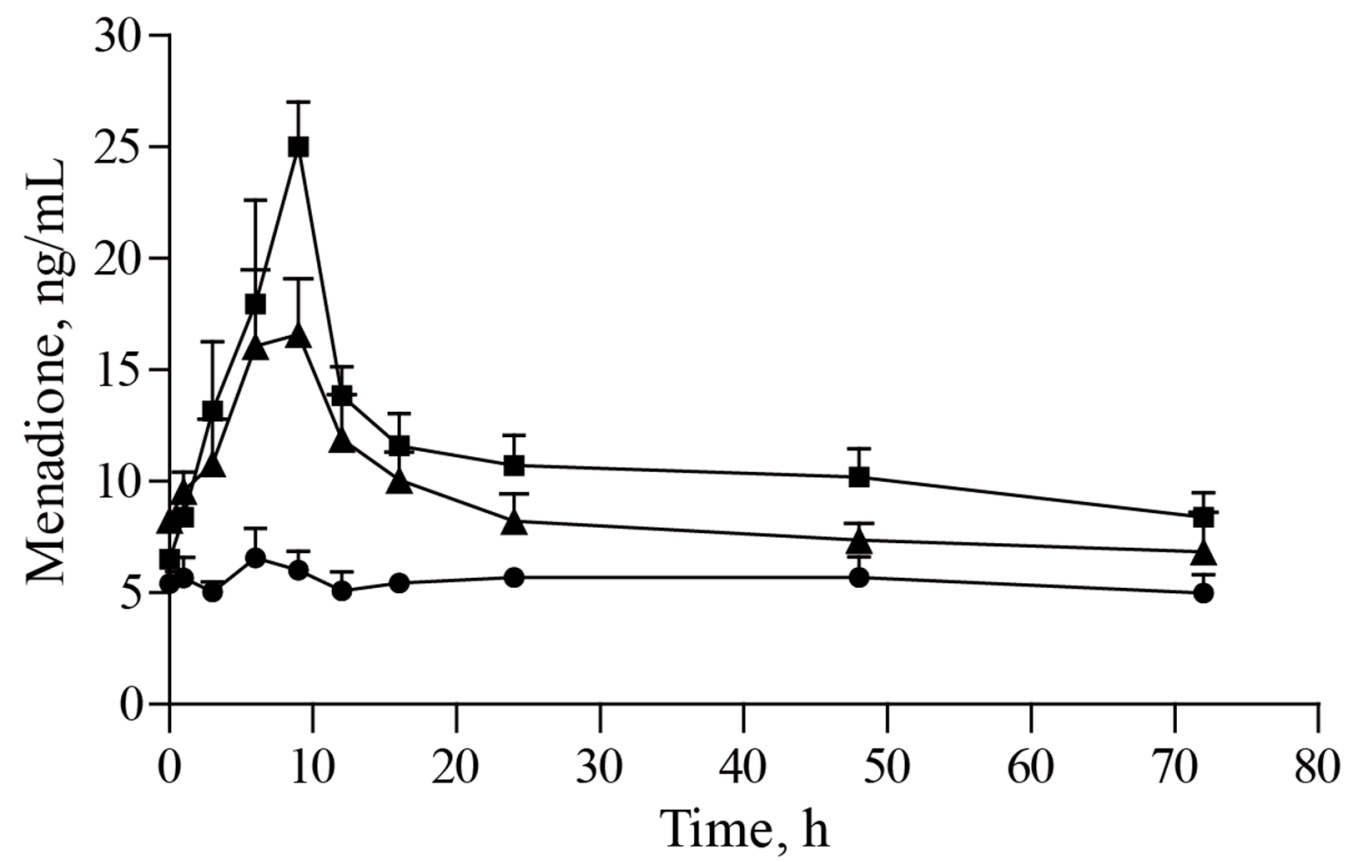

Figure 4. The plasma concentration of menadione versus time. The concentration of menadione in plasma from 0 to $72 \mathrm{~h}$ after oral placebo $(\bullet)$, non-microencapsulated vitamin supplement $(\boldsymbol{\square})$, and microencapsulated vitamin supplement $(\boldsymbol{\Lambda})$, respectively. Error bars represent standard deviations. 
Table 2. Pharmacokinetic parameters of plasma fat-soluble vitamin concentrations in pigs ${ }^{1}$.

\begin{tabular}{|c|c|c|c|c|}
\hline \multirow{2}{*}{ Parameter } & \multicolumn{2}{|c|}{ Oral Administration } & \multirow{2}{*}{ SEM } & \multirow{2}{*}{$p$-Value } \\
\hline & NMVS & MVS & & \\
\hline \multicolumn{5}{|l|}{ Retinol } \\
\hline $\mathrm{T}_{\max }, \mathrm{h}$ & 7.13 & 7.71 & 0.97 & 0.666 \\
\hline $\mathrm{C}_{\max }, \mu \mathrm{g} / \mathrm{mL}$ & 0.13 & 0.17 & 0.02 & 0.176 \\
\hline $\mathrm{AUC}, \mathrm{h} \times \mu \mathrm{g} / \mathrm{mL}$ & 2.15 & 3.66 & 0.56 & 0.071 \\
\hline $\mathrm{t}_{1 / 2 \beta}, \mathrm{h}$ & 25.17 & 40.98 & 18.56 & 0.544 \\
\hline MRT, h & 14.45 & 17.06 & 1.62 & 0.260 \\
\hline $\mathrm{F}, \%$ & & & 170.40 & \\
\hline \multicolumn{5}{|l|}{ 25-hydroxyvitamin $\mathrm{D}_{3}$} \\
\hline $\mathrm{T}_{\max }, \mathrm{h}$ & 12.33 & 12.00 & 4.48 & 0.961 \\
\hline $\mathrm{C}_{\max }, \mathrm{ng} / \mathrm{mL}$ & 27.61 & 28.42 & 0.70 & 0.461 \\
\hline $\mathrm{AUC}, \mathrm{h} \times \mu \mathrm{g} / \mathrm{mL}$ & 1717.82 & 1685.27 & 32.81 & 0.522 \\
\hline $\mathrm{t}_{1 / 2 \beta}, \mathrm{h}$ & 189.78 & 165.76 & 25.71 & 0.545 \\
\hline MRT, h & 35.48 & 34.81 & 0.43 & 0.337 \\
\hline $\mathrm{F}, \%$ & & & 98.11 & \\
\hline \multicolumn{5}{|l|}{$\alpha$-tocopherol } \\
\hline $\mathrm{T}_{\max }, \mathrm{h}$ & 8.50 & 11.50 & 1.80 & 0.267 \\
\hline $\mathrm{C}_{\max }, \mu \mathrm{g} / \mathrm{mL}$ & 0.74 & 1.10 & 0.05 & $<0.01$ \\
\hline $\mathrm{AUC}, \mathrm{h} \times \mu \mathrm{g} / \mathrm{mL}$ & 24.46 & 44.60 & 3.30 & $<0.01$ \\
\hline $\mathrm{t}_{1 / 2 \beta}, \mathrm{h}$ & 64.10 & 42.25 & 30.54 & 0.624 \\
\hline MRT, h & 23.45 & 30.19 & 1.39 & $<0.01$ \\
\hline $\mathrm{F}, \%$ & & & 182.39 & \\
\hline \multicolumn{5}{|l|}{ Menadione } \\
\hline $\mathrm{T}_{\max }, \mathrm{h}$ & 9.00 & 8.00 & 0.71 & 0.374 \\
\hline $\mathrm{C}_{\max }, \mathrm{ng} / \mathrm{mL}$ & 18.99 & 10.59 & 1.31 & 0.011 \\
\hline $\mathrm{AUC}, \mathrm{h} \times \mathrm{ng} / \mathrm{mL}$ & 413.10 & 236.00 & 21.86 & $<0.01$ \\
\hline $\mathrm{t}_{1 / 2 \beta}, \mathrm{h}$ & 74.27 & 31.49 & 18.50 & 0.177 \\
\hline MRT, h & 28.41 & 24.60 & 2.89 & 0.404 \\
\hline $\mathrm{F}, \%$ & & & 57.13 & \\
\hline
\end{tabular}

${ }_{1}^{1}$ NMVS, non-microencapsulated vitamin supplement; MVS, microencapsulated vitamin supplement; $\mathrm{T}_{\max }$, time of maximum observed concentration; $\mathrm{C}_{\max }$, maximum observed concentration; $\mathrm{AUC}$, area under the curve from the time of dosing to the time of the last observation. $\mathrm{t}_{1 / 2 \beta}$, elimination half-life; MRT, mean residence time from the time of dosing to the time of the last measurable concentration; F, mean relative bioavailability (AUC of microencapsulated vitamin supplement compared with AUC of non-microencapsulated vitamin supplement); SEM, standard error of mean.

\subsection{The Pharmacokinetics of Water-Soluble Vitamins}

All water-soluble vitamin showed typical appearance and disappearance with peak values after administration (Figures 5-10) regardless of encapsulation. But based on pharmacokinetics (Table 3), thiamine had lower $\mathrm{C}_{\max }, \mathrm{AUC}$, and $\mathrm{t}_{1 / 2 \beta}$ (tendency) in MVS than NMVS. Riboflavin had lower $C_{\max }$ and AUC in MVS than NMVS. Biotin had higher $\mathrm{C}_{\max }$ in NMVS than MVS. Pantothenic acid had higher $\mathrm{T}_{\max }$ in MVS than NMVS. Pyridoxal had higher $\mathrm{T}_{\max }$ and MRT in MVS than NMVS. Vitamin $\mathrm{B}_{12}$ had higher $\mathrm{T}_{\max }$ but lower $\mathrm{C}_{\max }$ in MVS than NMVS. Relative bioavailability of MVS to NMVS was $47.15 \%, 28.94 \%$, $101.31 \%, 90.94 \%, 67.96 \%$, and $86.06 \%$ for thiamine, riboflavin, pantothenic acid, pyridoxal, biotin, and vitamin $\mathrm{B}_{12}$, respectively. 


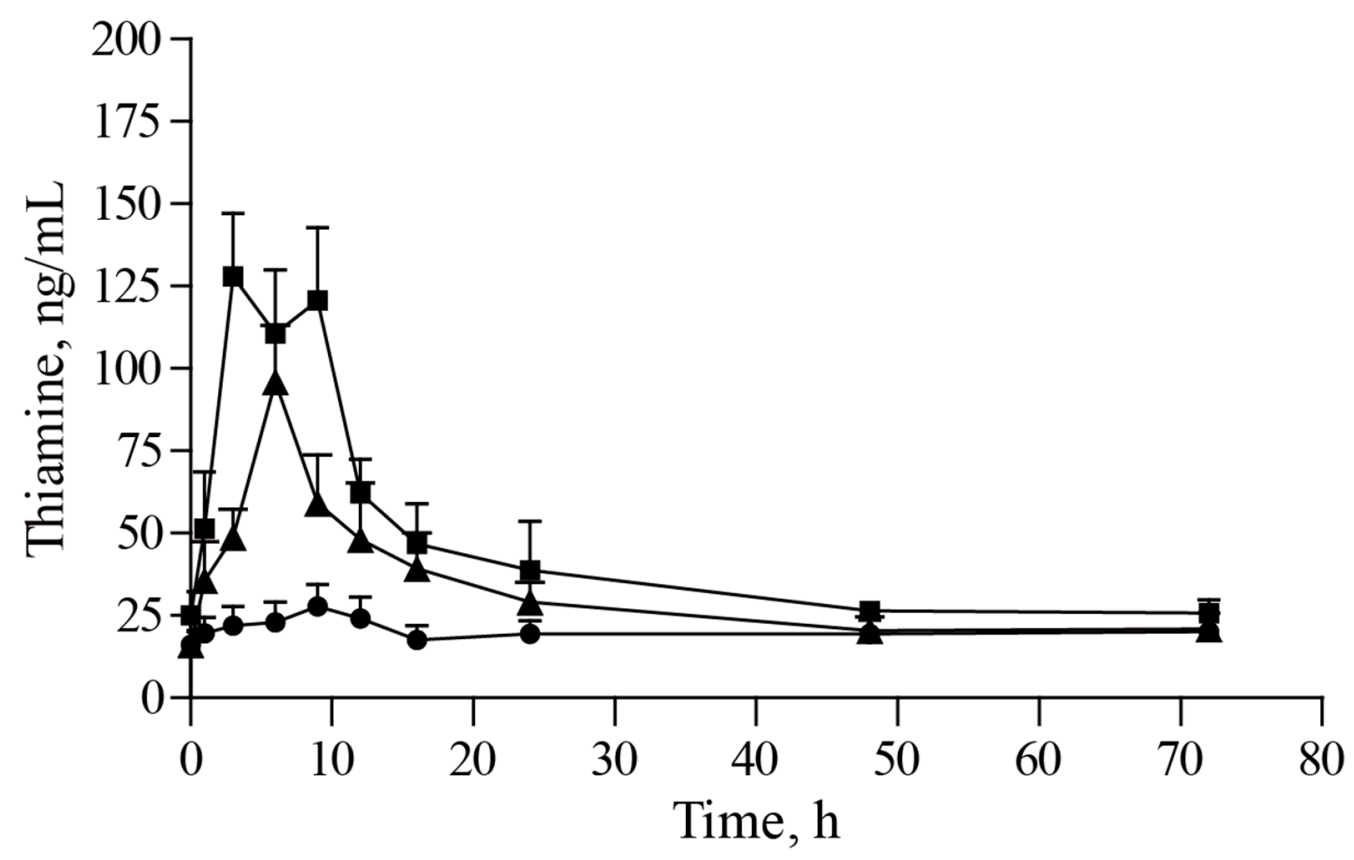

Figure 5. The plasma concentration of thiamine versus time. The concentration of thiamine in plasma from 0 to $72 \mathrm{~h}$ after oral placebo $(\bullet)$, non-microencapsulated vitamin supplement $(\mathbf{\square})$, and microencapsulated vitamin supplement $(\boldsymbol{\Lambda})$, respectively. Error bars represent standard deviations.

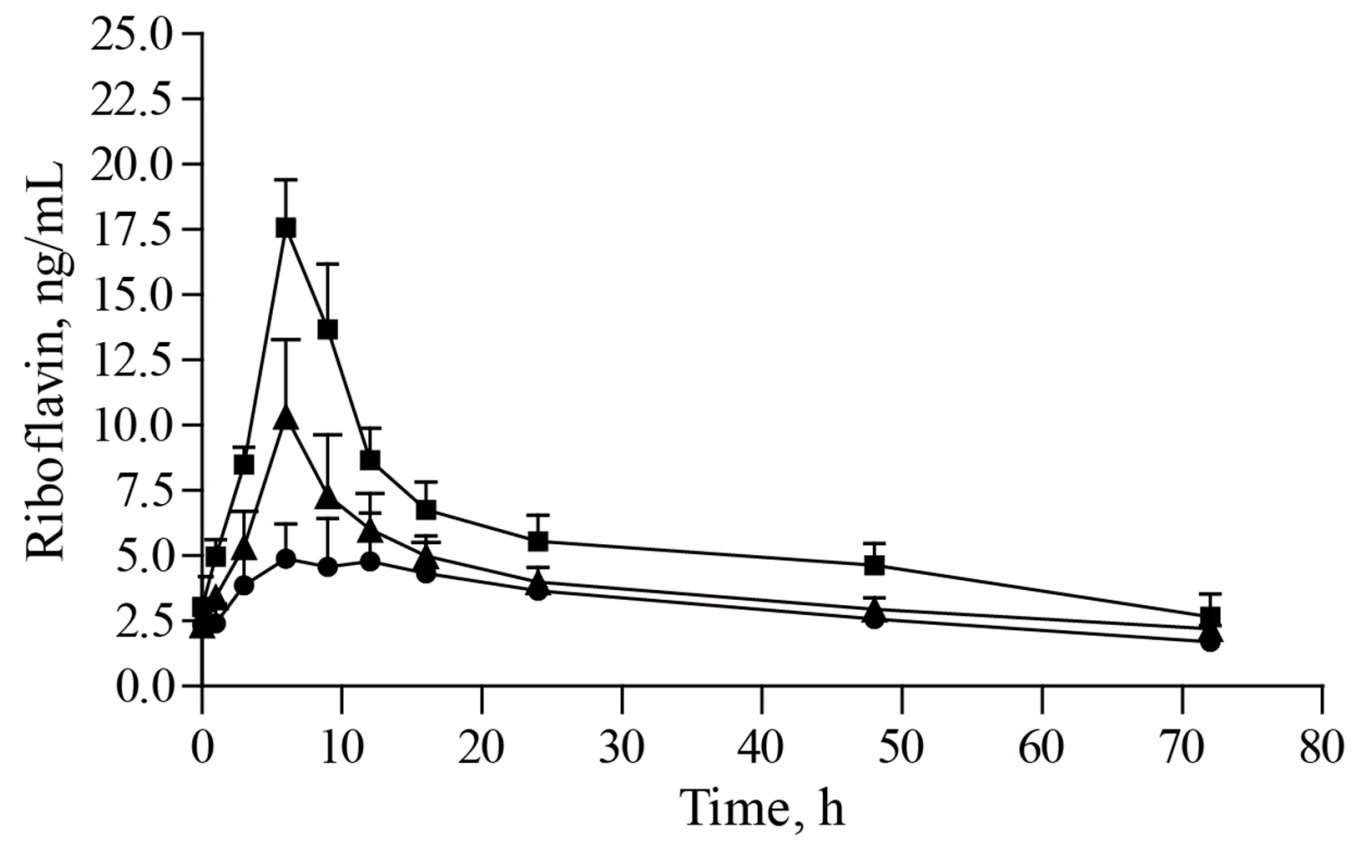

Figure 6. The plasma concentration of riboflavin versus time. The concentration of riboflavin in plasma from 0 to $72 \mathrm{~h}$ after oral placebo $(\bullet)$, non-microencapsulated vitamin supplement $(\mathbf{\square})$, and microencapsulated vitamin supplement $(\boldsymbol{\Lambda})$, respectively. Error bars represent standard deviations. 


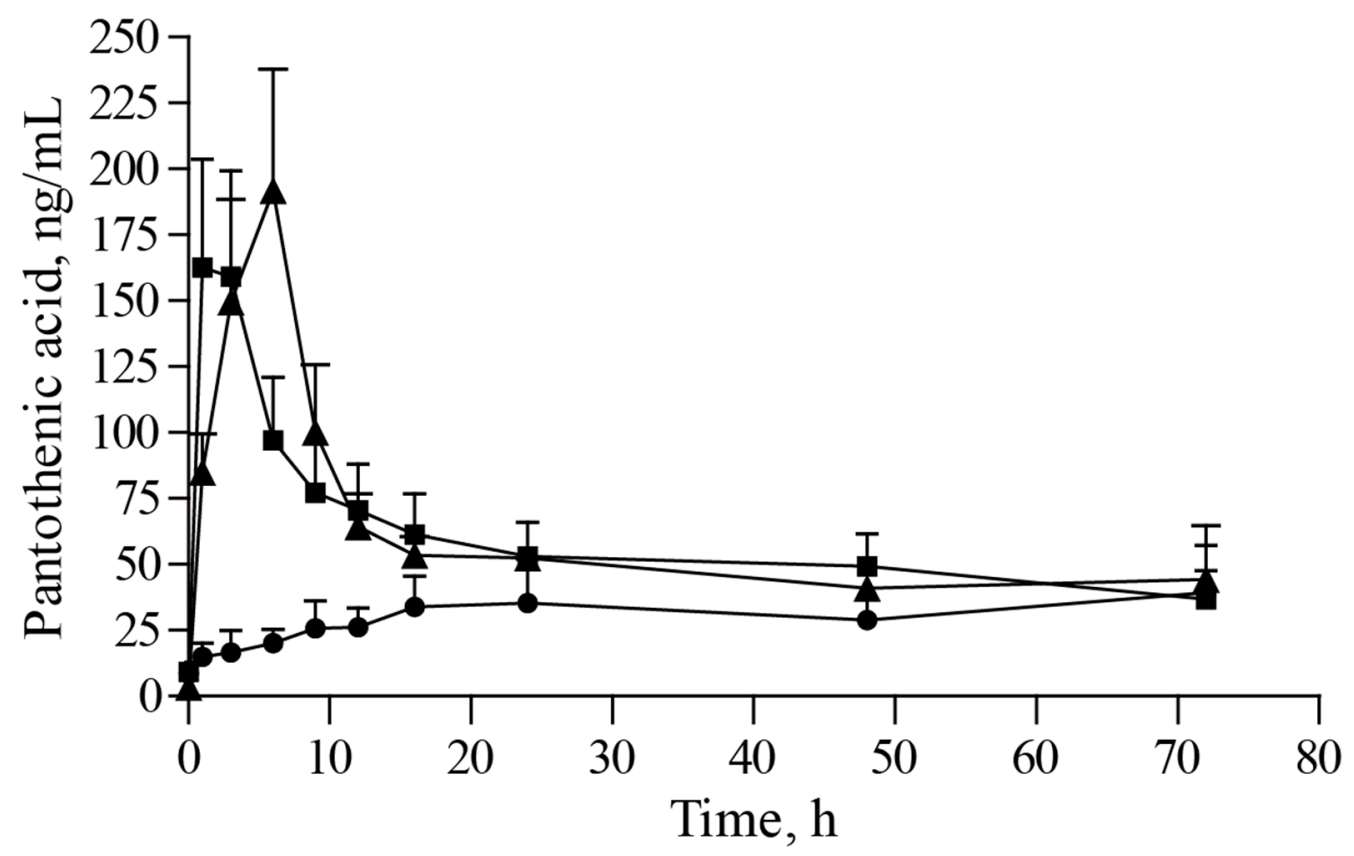

Figure 7. The plasma concentration of pantothenic acid versus time. The concentration of pantothenic acid in plasma from 0 to $72 \mathrm{~h}$ after oral placebo $(\bullet)$, non-microencapsulated vitamin supplement $(\boldsymbol{\square})$, and microencapsulated vitamin supplement $(\mathbf{\Lambda})$, respectively. Error bars represent standard deviations.

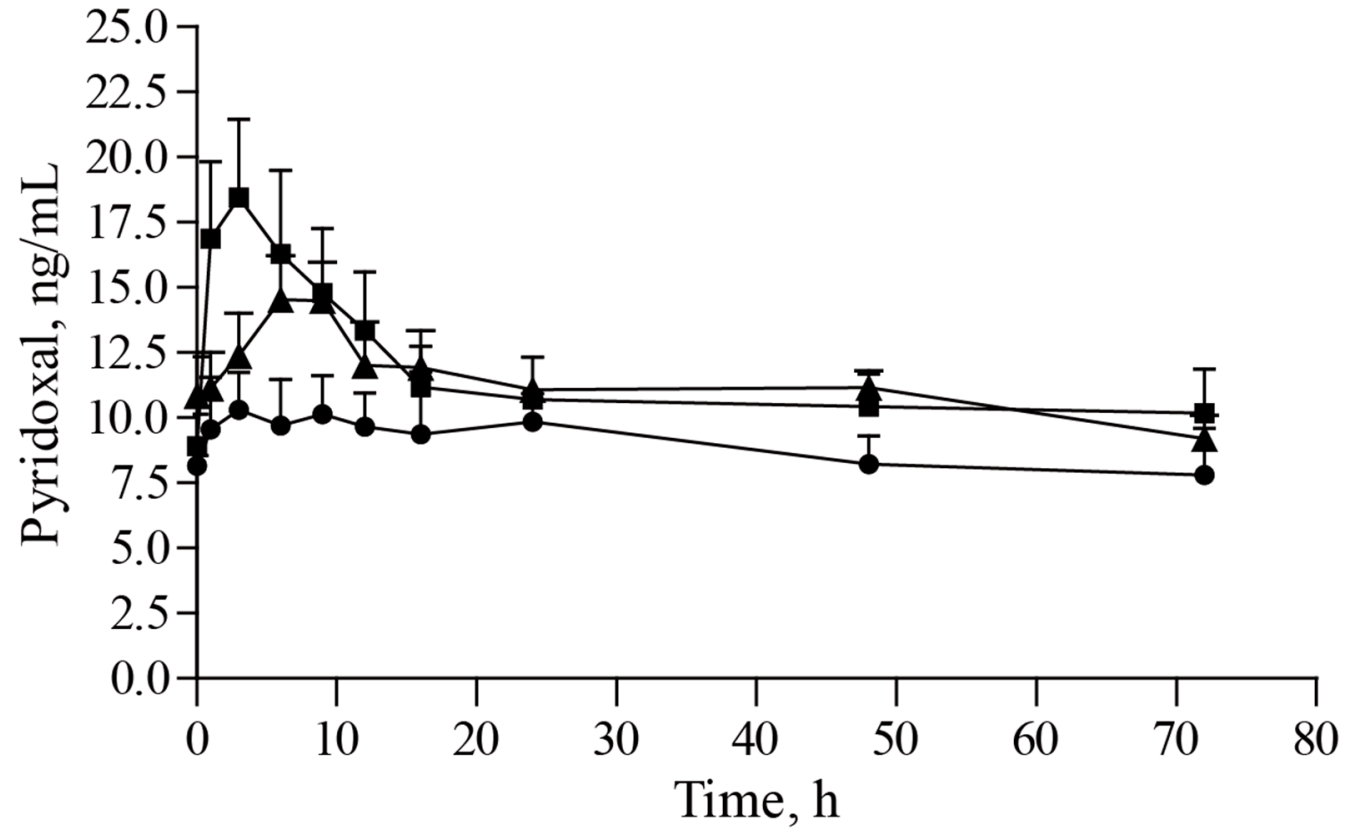

Figure 8. The plasma concentration of pyridoxal versus time. The concentration of pyridoxal in plasma from 0 to $72 \mathrm{~h}$ after oral placebo $(\bullet)$, non-microencapsulated vitamin supplement $(\mathbf{\square})$, and microencapsulated vitamin supplement $(\boldsymbol{\Lambda})$, respectively. Error bars represent standard deviations. 


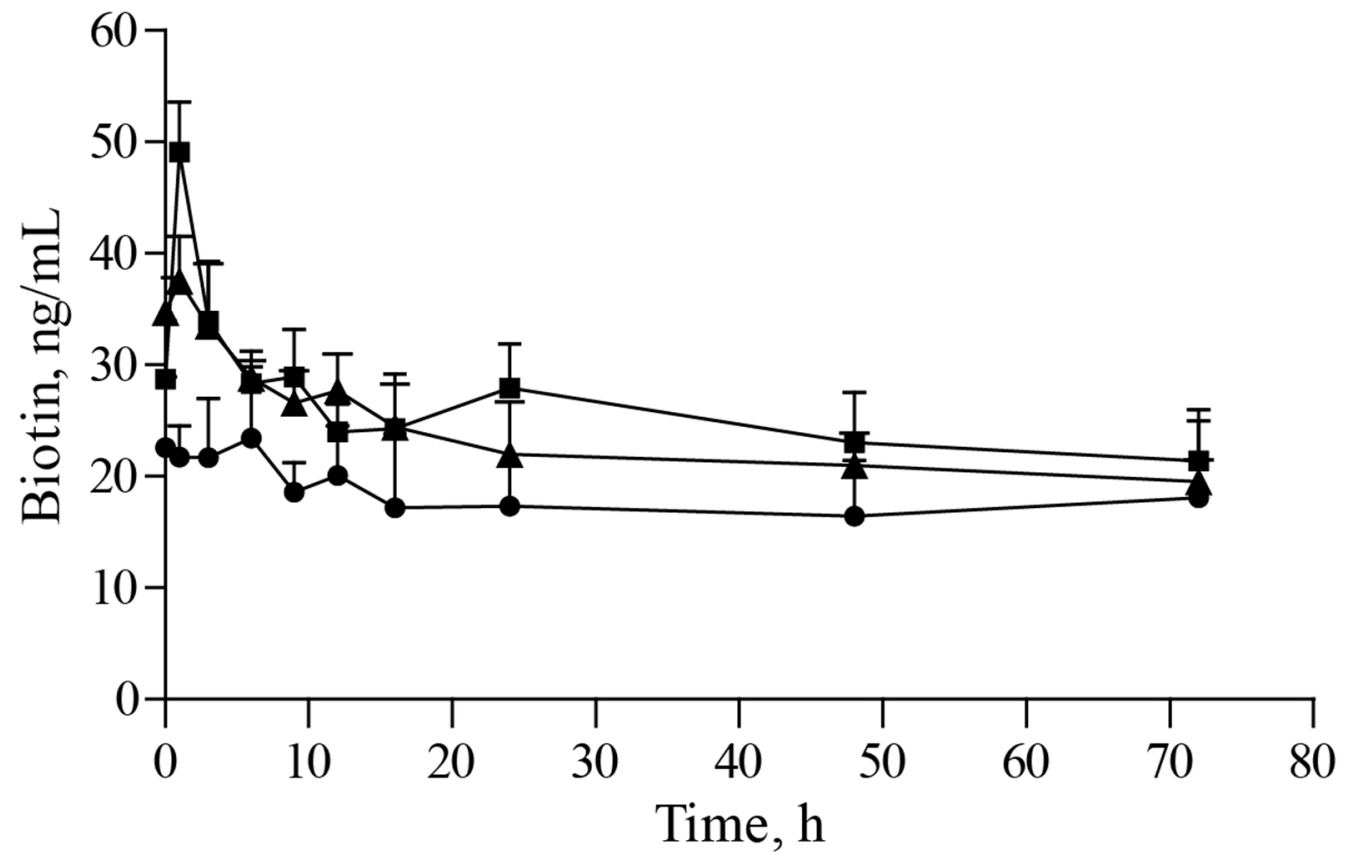

Figure 9. The plasma concentration of biotin versus time. The concentration of biotin in plasma from 0 to $72 \mathrm{~h}$ after oral placebo $(\bullet)$, non-microencapsulated vitamin supplement $(\boldsymbol{\square})$, and microencapsulated vitamin supplement $(\mathbf{\Lambda})$, respectively. Error bars represent standard deviations.

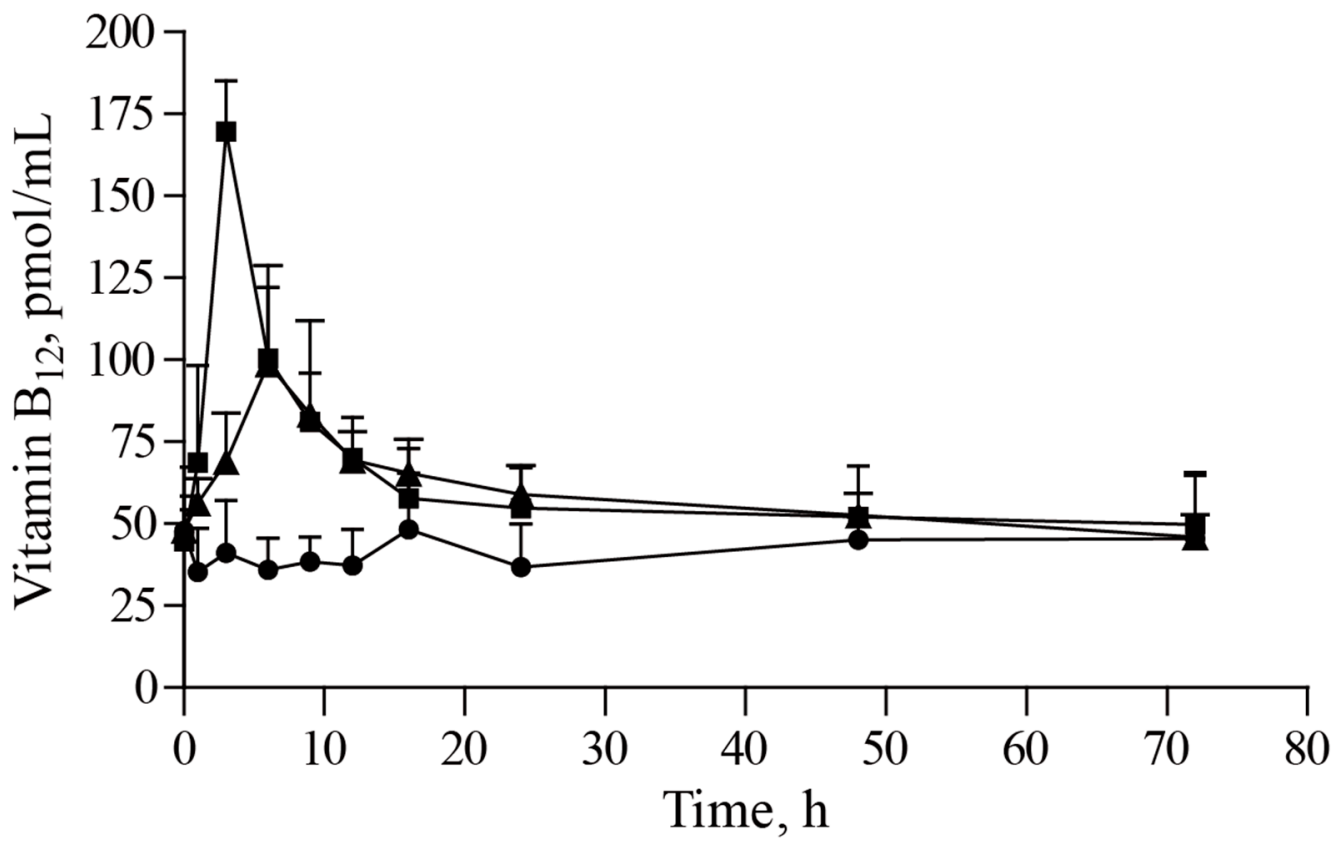

Figure 10. The plasma concentration of vitamin $B_{12}$ versus time. The concentration of vitamin $B_{12}$ in plasma from 0 to $72 \mathrm{~h}$ after oral placebo $(\bullet)$, non-microencapsulated vitamin supplement $(\boldsymbol{\square})$, and microencapsulated vitamin supplement $(\boldsymbol{\Lambda})$, respectively. Error bars represent standard deviations. 
Table 3. Pharmacokinetic parameters of plasma water-soluble vitamin concentrations in pigs ${ }^{1}$.

\begin{tabular}{|c|c|c|c|c|}
\hline \multirow{2}{*}{ Parameter } & \multicolumn{2}{|c|}{ Oral Administration } & \multirow{2}{*}{ SEM } & \multirow{2}{*}{$p$-Value } \\
\hline & NMVS & MVS & & \\
\hline \multicolumn{5}{|l|}{ Thiamine } \\
\hline $\mathrm{T}_{\max }, \mathrm{h}$ & 6.00 & 6.00 & 1.55 & NS \\
\hline $\mathrm{C}_{\max }, \mathrm{ng} / \mathrm{mL}$ & 112.74 & 73.07 & 9.52 & 0.025 \\
\hline $\mathrm{AUC}, \mathrm{h} \times \mathrm{ng} / \mathrm{mL}$ & 1713.26 & 807.85 & 146.54 & $<0.01$ \\
\hline $\mathrm{t}_{1 / 2 \beta}, \mathrm{h}$ & 25.50 & 13.48 & 4.50 & 0.099 \\
\hline MRT, h & 17.19 & 14.54 & 1.44 & 0.224 \\
\hline $\mathrm{F}, \%$ & & & 47.15 & \\
\hline \multicolumn{5}{|l|}{ Riboflavin } \\
\hline $\mathrm{T}_{\max }, \mathrm{h}$ & 6.00 & 6.00 & - & NS \\
\hline $\mathrm{C}_{\max }, \mathrm{ng} / \mathrm{mL}$ & 12.68 & 5.46 & 1.41 & 0.023 \\
\hline $\mathrm{AUC}, \mathrm{h} \times \mathrm{ng} / \mathrm{mL}$ & 200.70 & 58.08 & 20.93 & $<0.01$ \\
\hline $\mathrm{t}_{1 / 2 \beta}, \mathrm{h}$ & 27.77 & 31.88 & 6.90 & 0.695 \\
\hline MRT, h & 22.98 & 22.75 & 1.93 & 0.938 \\
\hline $\mathrm{F}, \%$ & & & 28.94 & \\
\hline \multicolumn{5}{|l|}{ Pantothenic acid } \\
\hline $\mathrm{T}_{\max }, \mathrm{h}$ & 1.00 & 6.00 & - & $<0.01$ \\
\hline $\mathrm{C}_{\max }, \mathrm{ng} / \mathrm{mL}$ & 147.80 & 171.65 & 25.16 & 0.539 \\
\hline $\mathrm{AUC}, \mathrm{h} \times \mathrm{ng} / \mathrm{mL}$ & 2022.69 & 2049.20 & 538.23 & 0.974 \\
\hline $\mathrm{t}_{1 / 2 \beta}, \mathrm{h}$ & 18.19 & 22.48 & 4.09 & 0.499 \\
\hline MRT, h & 16.09 & 15.59 & 3.08 & 0.914 \\
\hline $\mathrm{F}, \%$ & & & 101.31 & \\
\hline \multicolumn{5}{|l|}{ Pyridoxal } \\
\hline $\mathrm{T}_{\max }, \mathrm{h}$ & 3.00 & 6.00 & - & $<0.01$ \\
\hline $\mathrm{C}_{\max }, \mathrm{ng} / \mathrm{mL}$ & 8.16 & 4.84 & 1.41 & 0.171 \\
\hline $\mathrm{AUC}, \mathrm{h} \times \mathrm{ng} / \mathrm{mL}$ & 184.19 & 167.51 & 56.24 & 0.844 \\
\hline $\mathrm{t}_{1 / 2 \beta}, \mathrm{h}$ & 47.75 & 55.21 & 4.34 & 0.291 \\
\hline MRT, h & 29.86 & 33.94 & 0.66 & 0.012 \\
\hline $\mathrm{F}, \%$ & & & 90.94 & \\
\hline \multicolumn{5}{|l|}{ Biotin } \\
\hline $\mathrm{T}_{\max }, \mathrm{h}$ & 1.00 & 1.00 & - & NS \\
\hline $\mathrm{C}_{\max }, \mathrm{ng} / \mathrm{mL}$ & 27.37 & 15.82 & 2.45 & 0.029 \\
\hline $\mathrm{AUC}, \mathrm{h} \times \mathrm{ng} / \mathrm{mL}$ & 544.38 & 369.93 & 150.25 & 0.458 \\
\hline$t_{1 / 2 \beta}, h$ & 36.76 & 27.86 & 4.52 & 0.236 \\
\hline MRT, h & 26.92 & 24.12 & 3.93 & 0.641 \\
\hline $\mathrm{F}, \%$ & & & 67.96 & \\
\hline \multicolumn{5}{|l|}{ Vitamin $\mathrm{B}_{12}$} \\
\hline $\mathrm{T}_{\max }, \mathrm{h}$ & 3.00 & 8.00 & 0.97 & $<0.01$ \\
\hline $\mathrm{C}_{\max }, \mathrm{ng} / \mathrm{mL}$ & 128.39 & 67.54 & 11.74 & $<0.01$ \\
\hline $\mathrm{AUC}, \mathrm{h} \times \mathrm{ng} / \mathrm{mL}$ & 1373.14 & 1181.65 & 272.29 & 0.601 \\
\hline$t_{1 / 2 \beta}, h$ & 19.21 & 30.72 & 15.90 & 0.590 \\
\hline MRT, h & 15.11 & 19.82 & 4.18 & 0.408 \\
\hline $\mathrm{F}, \%$ & & & 86.06 & \\
\hline
\end{tabular}

${ }^{1}$ NMVS, non-microencapsulated vitamin supplement; MVS, microencapsulated vitamin supplement; $\mathrm{T}_{\max }$, time of maximum observed concentration; $C_{\max }$, maximum observed concentration; $A U C$, area under the curve from the time of dosing to the time of the last observation. $t_{12 \beta}$, elimination half-life; MRT, mean residence time from the time of dosing to the time of the last measurable concentration; F, mean relative bioavailability (AUC of microencapsulated vitamin supplement compared with AUC of non-microencapsulated vitamin supplement) SEM, standard error of mean; NS, no significant. 


\section{Discussion}

Pharmacokinetic parameters are assessed by monitoring variations in the concentration of a nutrient or its metabolites in physiological fluids, which reflects the duration of action of the nutrients in the host [17]. Vitamins exhibiting the appropriate pharmacokinetic parameters are more likely to exert its biofunction [18], but there is limited information about plasma vitamin behavior after single oral multivitamin supplement for pigs. A potential limitation of this study is the interaction between native vitamins and synthesized vitamins. The current study found that the blood distribution of retinol after oral vitamin administration was consistent with previous research [14,19]. Jang et al. investigated temporal plasma vitamin status in a 20-day trial period for suckling pigs after high dose of fat-soluble vitamins administration [20]. They reported that the plasma retinol level was not affected by vitamin A administration, which is contradictory to the results of the present study. This may be explained by saying that these sampling time points in the previous study were not ideal for plasma retinol kinetics. Raila et al. studied pharmacokinetic behavior of vitamin A in dogs [21]; they observed that the peak plasma concentration was observed at $8 \mathrm{~h}$ after a single oral $3000 \mathrm{IU} / \mathrm{kg}$ vitamin A, and then plasma vitamin A was decreased until reaching $72 \mathrm{~h}$. Jang et al. elucidated that the retinol concentration in blood was associated with physiological status and performance of pig [22]. The present study was designed to determine the relative bioavailability of microencapsulated supplement compared to normal form of supplement. The determination of AUC is the method commonly used by regulatory agencies to assess extent of nutrient absorption after single-dose administration of oral products. There was no significant difference in the AUC of vitamin A from the two different forms of supplements, but it showed a tendency to increase when vitamin A was formulated with lipid matrix microencapsulation. This observation indicated that microencapsulation for vitamin A has potential to improve its bioavailability, which is consistent with a previous study [23]. The plasma 25-hydroxyvitamin $\mathrm{D}_{3}$ concentrations peaked at $12 \mathrm{~h}$ after administration of vitamin $\mathrm{D}_{3}$ and the slow distribution of 25-hydroxyvitamin $\mathrm{D}_{3}$, this peak time was earlier than that reported by Jang et al. [20,24]; they revealed that the maximum plasma concentration of 25-hydroxyvitamin $D_{3}$ occurred from days 1 to 3 after single oral administration of $40,000 \mathrm{IU}$ vitamin $\mathrm{D}_{3}$. This difference may be attributed to the dosage of vitamin $\mathrm{D}_{3}$; a high dose of vitamin $\mathrm{D}_{3}$ intake may decrease vitamin $\mathrm{D}$ binding protein levels in circulating [25]. The carrier protein for vitamin $\mathrm{D}$ and its analogue in the body, vitamin $\mathrm{D}$ binding protein, is responsible for the half-life for 25-hydroxyvitamin $\mathrm{D}_{3}$ in the blood by acting as a reservoir and promoting the reabsorption of vitamin $\mathrm{D}$ in the kidney [26]. In the present study, it was observed that the two forms of vitamin $\mathrm{D}_{3}$ have similar bioavailability, which exceeded the pre-experimental assumptions. A possible explanation for this might be that the metabolism of vitamin $\mathrm{D}$ in the animal body and coating materials as well as interaction mechanisms. The $\alpha$-tocopherol concentration in blood reflected the vitamin $\mathrm{E}$ status; the plasma $\alpha$-tocopherol reached the peak concentration about $12 \mathrm{~h}$ after oral administration of vitamin E. After this peak, the plasma $\alpha$-tocopherol concentration gradually decreased. The slow appearance of the peak value is in line with earlier findings $[13,16]$. The plasma $\alpha$-tocopherol from oral microencapsulated supplement were markedly higher than that from the oral normal form of the supplement, which is consistent with our previous study [14]. The increased AUC and $\mathrm{C}_{\max }$ indicated that microencapsulation for vitamin $\mathrm{E}$ could improve its bioavailability by rapidly increasing the $\alpha$-tocopherol mass in circulation. The MRT is used to estimate the average time a nutrient molecule spends in the body. In the present study, microencapsulation for vitamin $\mathrm{E}$ achieved slow release and increased bioavailability of vitamin $E$ to the outside, which is one of the aims for the the application of this technique. To our knowledge, this is the first detailed pharmacokinetic study for oral supplementation with vitamin $\mathrm{K}_{3}$ in pigs. It was observed that oral vitamin supplements showed the maximum plasma menadione concentrations at 8-9 h. The $C_{\max }$ and AUC values of vitamin $\mathrm{K}_{3}$ from oral non-microencapsulated supplement were markedly higher than that from oral lipid matrix microencapsulated supplement, and the mean relative bioavailability from microencapsulated vitamin $\mathrm{K}$ is 
half of that from non-microencapsulated vitamin $\mathrm{K}(\mathrm{F}=57.13 \%)$, this result is out of our expectation. Menadione (vitamin $\mathrm{K}_{3}$ ) is a synthetic form of vitamin K. In the vitamin industry, several synthetic analogues and derivatives of menadione have been used. Menadione sodium bisulfite is a water-soluble salt of menadione, which is used extensively as vitamin $\mathrm{K}_{3}$ fortification in supplements and pharmaceutical products. It is possible, therefore, that lipid matrix microencapsulation for water-soluble substances may not facilitate digestion and absorption of this substance (e.g., menadione sodium bisulfite) for pigs.

Contrary to expectations, this study did not find the typical pharmacokinetic profiles for folic acid and niacin. A possible explanation for this might be that the analytical method is not sensitive enough for detecting these targeted metabolites after single oral doses of these vitamins. The plasma water-soluble vitamin concentrations were affected by microencapsulation; it was a reduction for the bioavailability of thiamine, riboflavin, biotin, and vitamin $B_{12}$ from microencapsulated supplement. This discrepancy could be attributed to the coating material used in encapsulation. Lipid matrix microencapsulation coats the vitamins with lipid and it needs to be degraded in order for vitamins to be released from that coating and then absorbed. For lipid, emulsification is important for lipid digestion and absorption as lipid is hydrophobic. Fat-soluble vitamins are derived lipids so they are absorbed with lipid, but water-soluble vitamins are hydrophilic. If water-soluble vitamins are coated with lipid, it means that a lipid matrix should be degraded first and then watersoluble vitamins can be absorbed. No microencapsulation means no lipid coating so the water-soluble vitamins do not need to have lipid-coating degradation. This could be one explanation why there was a contrast results in $\mathrm{C}_{\max }$ and relative bioavailability between fat-soluble and water-soluble vitamins.

In this study, we first carried out a pharmacokinetic trial of B complex vitamins, and then presented its plasma kinetics, although little information is available in pigs. For pharmacokinetic characteristic of thiamine from supplement, it shows an immediate increase in thiamine in plasma after feeding vitamin supplements, both treatment groups showed typical pharmacokinetic profiles of thiamine. A similar phenomenon was observed in human experiments; concentrations of thiamine in plasma increased after single-dose administration [27]. Plasma thiamine concentrations peaked at $6 \mathrm{~h}$ after feeding, which was slightly later than the human trial [27-29]. This may be due to delayed feeding rate and stomach emptying. A previous study evaluating riboflavin bioavailability from supplements in humans, they observed that the maximum plasma riboflavin concentration was reached at 1.4 to $4.6 \mathrm{~h}$, and the initial absorption of riboflavin occurred at the same rate from a controlled release dosage form [30].

Vitamin $\mathrm{B}_{6}$ as a coenzyme involved in amino acids, fats, and carbohydrate metabolism. It is essential for RNA and DNA synthesis and involved in the synthesis of niacin from tryptophan. In practice, pyridoxine hydrochloride is generally used as a vitamin $\mathrm{B}_{6}$ source. After oral administration of pyridoxine hydrochloride, its metabolite pyridoxal rises rapidly in blood, followed by a rapid decrease. This result may be due to tissue uptake and phosphorylation [31]. These results from the present study corroborate the ideas of previous studies [31,32]; they suggested that the concentration of pyridoxal in plasma can be enhanced by increasing the intake of pyridoxine hydrochloride. Additionally, present study also aimed to characterize the pharmacokinetic properties of biotin and establish the pharmacokinetic model for different regimens. Results of the pharmacokinetic analysis showed that biotin is rapidly absorbed after oral supplement administration; both treatment groups showed typical pharmacokinetic kinetics of biotin. In accordance with the present results, single doses of biotin in capsules were rapidly absorbed and distributed in healthy adults [33]; they also suggested food effect was observed with increasing pharmacokinetic parameters. This factor may explain that the delay in absorption was longer in the animal experiment than clinic trial conditions. In blood, vitamin $B_{12}$ concentration increased after dietary intake of vitamin $B_{12}$. The vitamin $B_{12}$ responses after oral vitamin supplement are also in line with previous study [34]. They observed pharmacokinetic changes of vitamin $B_{12}$ concentration in arterial plasma. After a meal, plasma vitamin $B_{12}$ decreased to reach baseline between 
15 and $18 \mathrm{~h}$ post-meal. Kinetic behavior of vitamin $\mathrm{B}_{12}$ in peripheral venous blood were reported in humans [35] and showed a continuous increase from 1.5 to $6 \mathrm{~h}$ post-meal and then a plateau up to $12 \mathrm{~h}$ post-meal. This finding is contrary to previous studies which have suggested that different experimental models have different kinetic behavior of vitamin $B_{12}$. Besides, it is more likely that the reabsorption of vitamin $B_{12}$ in the gut, which affects the distribution of vitamin $B_{12}$ in the peripheral compartment. Besides, a previous study suggested that the food matrix affects the absorption of vitamin $B_{12}$; it would be related to the rate of the vitamin release from this food matrix in the intestine [36].

\section{Conclusions}

In summary, this study has provided direct information about plasma vitamin kinetics after single oral administration of vitamins. These results demonstrate that high blood levels of vitamin distribution can be completed by oral multivitamins supplement administration. Lipid matrix microencapsulation is a feasible process to improve the bioavailability of vitamin E; vitamin $\mathrm{D}$, vitamin $\mathrm{K}$ and water-soluble vitamins may be sufficient to enhance its utilization for pigs without lipid matrix microencapsulation. More research is needed to be carried out to find more appropriate coating materials for water-soluble vitamin delivery.

Author Contributions: Conceptualization, P.Y. and Y.M.; methodology, Y.M.; validation, P.Y. and Y.M.; formal analysis, P.Y. and H.W.; investigation, P.Y., L.L. and H.W.; writing-original draft preparation, P.Y.; writing — review and editing, P.Y. and Y.M.; supervision, N.Z. and Y.M.; funding acquisition, Y.M. All authors have read and agreed to the published version of the manuscript.

Funding: This work is supported by Evaluation of Bioavailability of New Feed Additives, a project that has received funding from China Agricultural University (grant number: 201705510410056) and Ministry of Agriculture and Rural Affairs (grant number: 21178259). The National Natural Science Foundation (grant number: 32072740) partly supported this work.

Institutional Review Board Statement: The experimental protocol involving animals were performed in accordance with the China Agricultural University Laboratory Animal Welfare and Animal Experimental Ethical Inspection Committee (protocol number: AW01010202-1).

Data Availability Statement: The data presented in this study are available on request.

Conflicts of Interest: The authors declare no conflict of interest.

\section{References}

1. Combs, G.F., Jr. The Vitamins - Fundamental Aspects in Nutrition and Health, 4th ed.; Academic Press: Cambridge, MA, USA, 2016; p. 1570.

2. Jeong, J.H.; Hong, J.S.; Han, T.H.; Fang, L.H.; Chung, W.L.; Kim, Y.Y. Effects of dietary vitamin levels on physiological responses, blood profiles, and reproductive performance in gestating sows. J. Anim. Sci. Technol. 2019, 61, 294-303. [CrossRef]

3. Gattu, S.; Bang, Y.-J.; Pendse, M.; Dende, C.; Chara, A.L.; Harris, T.A.; Wang, Y.; Ruhn, K.A.; Kuang, Z.; Sockanathan, S.; et al. Epithelial retinoic acid receptor $\beta$ regulates serum amyloid A expression and vitamin A-dependent intestinal immunity. Proc. Natl. Acad. Sci. USA 2019, 116, 10911-10916. [CrossRef]

4. Upadhaya, S.D.; Kim, I.H. Importance of micronutrients in bone health of monogastric animals and techniques to improve the bioavailability of micronutrient supplements: A review. Asian Australas J. Anim. Sci. 2020, 33, 1885-1895. [CrossRef]

5. Teleki, A.; Hitzfeld, A.; Eggersdorfer, M. 100 years of vitamins: The science of formulation is the key to functionality. Kona Powder Part J. 2012, 30, 144-163. [CrossRef]

6. National Research Council. Nutrient Requirements of Swine, 11th ed.; National Research Council of the National Academies: Washington, DC, USA, 2012.

7. Liu, H.; Cui, S.W.; Chen, M.; Li, Y.; Liang, R.; Xu, F.; Zhong, F. Protective approaches and mechanisms of microencapsulation to the survival of probiotic bacteria during processing, storage and gastrointestinal digestion: A review. Crit. Rev. Food Sci. Nutr. 2019, 59, 2863-2878. [CrossRef]

8. Wilson, N.; Shah, N.P. Microencapsulation of vitamins. ASEAN Food J. 2007, 14, 1-14.

9. Choi, J.; Wang, L.; Ammeter, E.; Lahaye, L.; Liu, S.; Nyachoti, M.; Yang, C. Evaluation of lipid matrix microencapsulation for intestinal delivery of thymol in weaned pigs. Transl. Anim. Sci. 2020, 4, 411-422. [CrossRef]

10. Yang, F.; Zhang, S.; Kim, S.W.; Ren, C.; Tian, M.; Cheng, L.; Song, J.; Chen, J.; Chen, F.; Guan, W. Fat encapsulation enhances dietary nutrients utilization and growth performance of nursery pigs. J. Anim. Sci. 2018, 96, 3337-3347. [CrossRef] 
11. Gamboa, O.D.; Gonçalves, L.G.; Grosso, C.F. Microencapsulation of tocopherols in lipid matrix by spray chilling method. Procedia Food Sci. 2011, 1, 1732-1739. [CrossRef]

12. Dhakal, S.P.; He, J. Microencapsulation of vitamins in food applications to prevent losses in processing and storage: A Review. Food Res. Int. 2020, 137, 109326. [CrossRef] [PubMed]

13. van Kempen, T.A.T.G.; de Bruijn, C.; Reijersen, M.H.; Traber, M.G. Water-soluble all-rac $\alpha$-tocopheryl-phosphate and fat-soluble all-rac $\alpha$-tocopheryl-acetate are comparable vitamin E sources for swine. J. Anim. Sci. 2018, 96, 3330-3336. [CrossRef]

14. Yang, P.; Zhao, J.; Wang, H.; Li, L.; Ma, Y. Effects of vitamin forms and levels on vitamin bioavailability and growth performance in piglets. Appl. Sci. 2020, 10, 4903. [CrossRef]

15. Yang, P.; Wang, H.K.; Li, L.X.; Ma, Y.X. The strategies for the supplementation of vitamins and trace minerals in pig production: Surveying major producers in China. Asian Australas J. Anim. Sci. 2020. [CrossRef]

16. van Kempen, T.A.T.G.; Reijersen, M.H.; De Bruijn, C.; De Smet, S.; Michiels, J.; Traber, M.G.; Lauridsen, C. Vitamin E plasma kinetics in swine show low bioavailability and short half-life of all-rac- $\alpha$-tocopheryl acetate. J. Anim. Sci. 2016, 94, 4188-4195. [CrossRef] [PubMed]

17. Alpers, D.H. Vitamins as drugs: The importance of pharmacokinetics in oral dosing. Curr. Opin. Gastroenterol. 2011, 27, 146-151. [CrossRef]

18. Rejinold, N.S.; Kim, H.K.; Isakovic, A.F.; Gater, D.L.; Kim, Y.C. Therapeutic vitamin delivery: Chemical and physical methods with future directions. J. Control. Release 2019, 298, 83-98. [CrossRef] [PubMed]

19. Gannon, B.M.; Davis, C.R.; Nair, N.; Grahn, M.; Tanumihardjo, S.A. Single high-dose vitamin a supplementation to neonatal piglets results in a transient dose response in extrahepatic organs and sustained increases in liver stores. J. Nutr. 2017, 147, 798-806. [CrossRef] [PubMed]

20. Jang, Y.D.; Ma, J.Y.; Monegue, J.S.; Monegue, H.J.; Stuart, R.L.; Lindemann, M.D. Temporal plasma vitamin concentrations are altered by fat-soluble vitamin administration in suckling pigs. J. Anim. Sci. 2015, 93, 5273-5282. [CrossRef] [PubMed]

21. Raila, J.; Radon, R.; Trüpschuch, A.; Schweigert, F.J. Retinol and retinyl ester responses in the blood plasma and urine of dogs after a single oral dose of vitamin A. J. Nutr. 2018, 132, 1673S-1675S. [CrossRef] [PubMed]

22. Jang, Y.D.; Rotering, M.J.; Isensee, P.K.; Rinholen, K.A.; Boston-Denton, C.J.; Kelley, P.G.; Stuart, R.L. Distribution of injected fat-soluble vitamins in plasma and tissues of nursery pigs. Asian Australas J. Anim. Sci. 2020, 33, 1985-1990. [CrossRef] [PubMed]

23. Gonçalves, A.; Estevinho, B.N.; Rocha, F. Microencapsulation of vitamin A: A review. Trends Food Sci. Tech. 2016, 51, 76-87. [CrossRef]

24. Jang, Y.D.; Ma, J.; Lu, N.; Lim, J.; Monegue, H.J.; Stuart, R.L.; Lindemann, M.D. Administration of vitamin $\mathrm{D}_{3}$ by injection or drinking water alters serum 25-hydroxycholecalciferol concentrations of nursery pigs. Asian Australas J. Anim. Sci. 2018, 31, 278-286. [CrossRef] [PubMed]

25. Chen, P.Z.; Li, M.; Duan, X.H.; Jia, J.Y.; Li, J.Q.; Chu, R.A.; Yu, C.; Han, J.H.; Wang, H. Pharmacokinetics and effects of demographic factors on blood $25(\mathrm{OH}) \mathrm{D}_{3}$ levels after a single orally administered high dose of vitamin $\mathrm{D}_{3}$. Acta Pharmacol. Sin. 2016, 37, 1509-1515. [CrossRef]

26. Christakos, S.; Dhawan, P.; Verstuyf, A.; Verlinden, L.; Carmeliet, G. Vitamin D: Metabolism, molecular mechanism of action, and pleiotropic effects. Physiol. Rev. 2016, 96, 365-408. [CrossRef] [PubMed]

27. Xie, F.; Cheng, Z.; Li, S.; Liu, X.; Guo, X.; Yu, P.; Gu, Z. Pharmacokinetic study of benfotiamine and the bioavailability assessment compared to thiamine hydrochloride. J. Clin. Pharmacol. 2014, 54, 688-695. [CrossRef] [PubMed]

28. Smithline, H.A.; Donnino, M.; Greenblatt, D.J. Pharmacokinetics of high-dose oral thiamine hydrochloride in healthy subjects. BMC Clin. Pharmacol. 2012, 12, 4. [CrossRef]

29. Park, W.S.; Lee, J.; Hong, T.; Park, G.; Youn, S.; Seo, Y.; Lee, S.; Han, S. Comparative pharmacokinetic analysis of thiamine and its phosphorylated metabolites administered as multivitamin preparations. Clin. Ther. 2016, 38, 2277-2285. [CrossRef]

30. Kagan, L.; Lapidot, N.; Afargan, M.; Kirmayer, D.; Moor, E.; Mardor, Y.; Friedman, M.; Hoffman, A. Gastroretentive Accordion Pill: Enhancement of riboflavin bioavailability in humans. J. Control. Release 2006, 113, 208-215. [CrossRef]

31. Zempleni, J. Pharmacokinetics of vitamin $\mathrm{B}_{6}$ supplements in humans. J. Am. Coll. Nutr. 1995, 14, 579-586. [CrossRef] [PubMed]

32. Thakker, K.M.; Sitren, H.S.; Gregory, J.F.; Schmidt, G.L.; Baumgartner, T.G. Dosage form and formulation effects on the bioavailability of vitamin E, riboflavin, and vitamin B-6 from multivitamin preparations. Am. J. Clin. Nutr. 1987, 45, 1472-1479. [CrossRef]

33. Paul, L.P.S.; Debruyne, D.; Bernard, D.; Mock, D.M.; Defer, G.L. Pharmacokinetics and pharmacodynamics of MD1003 (high-dose biotin) in the treatment of progressive multiple sclerosis. Expert Opin. Drug Metab. Toxicol. 2016, 12, 327-344. [CrossRef] [PubMed]

34. Matte, J.J.; Guay, F.; Le Floc'h, N.; Girard, C.L. Bioavailability of dietary cyanocobalamin (vitamin B12) in growing pigs. J. Anim. Sci. 2010, 88, 3936-3944. [CrossRef] [PubMed]

35. von Castel-Roberts, K.M.; Morkbak, A.L.; Nexo, E.; Edgemon, C.A.; Maneval, D.R.; Shuster, J.J.; Valentine, J.F.; Kauwell, G.P.; Bailey, L.B. Holo-transcobalamin is an indicator of vitamin B-12 absorption in healthy adults with adequate vitamin B-12 status. Am. J. Clin. Nutr. 2007, 85, 1057-1061. [CrossRef] [PubMed]

36. Dalto, D.B.; Audet, I.; Girard, C.L.; Matte, J.J. Bioavailability of vitamin $\mathrm{B}_{12}$ from dairy products using a pig model. Nutrients 2018, 10, 1134. [CrossRef] 